CAUSATION

\title{
Pregnancy within 8 months of a previous birth was associated with an increased rate of preterm birth
}

\author{
Basso O, Olsen J, Knudsen L, et al. Low birth weight and preterm birth after short interpregnancy intervals. Am J Obstet Gynecol
} 1998 Feb;178:259-63.

\section{Question}

Are short interpregnancy intervals, defined as $\leqslant 8$ months, associated with an increased risk of low birth weight or preterm delivery?

\section{Design}

Cohort study.

\section{Setting}

Denmark.

\section{Participants}

10187 women who had 2 births between 1980 and 1992. Exclusion criteria were multiple births, stillbirths, and incomplete records for birth weight and gestational age of the child.

\section{Assessment of risk factors}

Interpregnancy interval was defined as $\leqslant 4,4.01-8.00,8.01-$ $12.00,12.01-24.00,24.01-36.00$, and $>36$ months and calculated as the difference between the birthdate of the first child and estimated date of conception of the second child in the study pair. The interval 24.01-36.00 months was taken as the reference standard (odds ratio [OR] 1.0). Other risk factors were age of mother at second study birth, parity at first study birth, social status (low, medium, and high) at first study birth, change in social status between births (unchanged, decrease, or increase), infant death (first or second study child), and gestational age of the first study child.

\section{Main outcome measures}

Preterm birth and low birth weight for the second study child.

\section{Main results}

The table shows data on preterm births and low birth weight in the 6 categories of interpregnancy intervals. Unadjusted univariate analysis showed that the shortest intervals between pregnancies were associated with low birth weight and preterm delivery (table). After adjustment for age of the mother, parity, social status, change in social status between births, and gestational age of the second child when the outcome was low birth weight, the association between low birth weight and interpregnancy interval disappeared but the association for preterm birth persisted (for interval $\leqslant 4.00$ mo OR $3.60,95 \%$ CI 2.04 to 6.35 and for interval 4.01-8.00 mo OR 2.28, CI 1.49 to 3.48). The interpregnancy interval $\geqslant 36.01$ months was associated with low birth weight in multivariate analysis (OR 1.44, CI 1.00 to 2.07). 109 $(0.01 \%)$ of the first study children died within 1 year of birth; the interpregnancy interval was shorter for these women. Death of the second study child was not associated with interpregnancy interval.

\section{Conclusion}

Women who conceived a child within 8 months of a previous successful pregnancy had an increased risk of preterm delivery.

Rates and unadjusted odds ratios of preterm birth and low birth weight for interpregnancy intervals

\begin{tabular}{|c|c|c|c|c|}
\hline \multirow[b]{2}{*}{$\begin{array}{l}\text { Interval in } \\
\text { months }\end{array}$} & \multicolumn{2}{|c|}{ Preterm birth } & \multicolumn{2}{|c|}{ Low birth weight } \\
\hline & Prevalence & $\begin{array}{l}\text { Odds ratio } \\
(95 \% \text { CI })\end{array}$ & Prevalence & $\begin{array}{l}\text { Odds ratio } \\
(C I)\end{array}$ \\
\hline$\leqslant 4.00$ & $8.3 \%$ & $\begin{array}{l}3.04 \\
(1.61 \text { to } 5.73)\end{array}$ & $11.8 \%$ & $\begin{array}{l}3.71 \\
\text { (2.14 to } 6.42)\end{array}$ \\
\hline $4.01-8.00$ & $5.1 \%$ & $\begin{array}{l}1.78 \\
(1.08 \text { to } 2.92)\end{array}$ & $7.7 \%$ & $\begin{array}{l}2.32 \\
(1.53 \text { to } 3.52)\end{array}$ \\
\hline $8.01-12.00$ & $3.3 \%$ & $\begin{array}{l}1.15 \\
(0.72 \text { to } 1.83)^{*}\end{array}$ & $4.0 \%$ & $\begin{array}{l}1.16 \\
(0.76 \text { to } 1.78) *\end{array}$ \\
\hline $12.01-24.00$ & $2.6 \%$ & $\begin{array}{l}0.91 \\
(0.66 \text { to } 1.25)^{*}\end{array}$ & $3.4 \%$ & $\begin{array}{l}0.97 \\
(0.73 \text { to } 1.30)^{*}\end{array}$ \\
\hline $\begin{array}{l}24.01-36.00 \\
\geqslant 36.01\end{array}$ & $\begin{array}{l}2.9 \% \\
4.2 \%\end{array}$ & $\begin{array}{l}1.00 \\
1.45 \\
\text { (1.09 to } 1.93)\end{array}$ & $\begin{array}{l}3.5 \% \\
3.9 \%\end{array}$ & $\begin{array}{l}1.00 \\
1.13 \\
(0.86 \text { to } 1.48)^{*}\end{array}$ \\
\hline
\end{tabular}

*Not significant.

Source of funding: Danish National Research Council.

For correspondence:Dr O Basso, The Danish Epidemiology Science Centre at the Department of Eprdemiology and Social Medicine, Aarhus University, Hoeoh-Guldberg Gade 10, DK 8000, Aarhus Denmark. Fax +4586131580

\section{Commentary}

The preterm birth of a baby and the complex and prolonged care that may be required by such an infant can be distressing to the child's family. Good information about risk factors for preterm birth may improve maternity care outcomes and lead to recommendations for prevention. Basso et al have speculated on the relation between interpregnancy interval and pregnancy outcomes.

This large study overcomes some of the problems of confounding (where the influence of factors other than interpregnancy interval may have influenced the results). The study accounted for parity, mother's age, and socioeconomic status but did not account for some important confounders such as smoking and nutrition. The accuracy of gestational age data may be questionable. However, the increased risk of low birth weight before adjustment for gestational age supports a relation between short interpregnancy intervals and increased risk of preterm delivery.

As the authors note, this study disagrees with previous studies with regard to the relation between short interpregnancy interval and birth weight and fetal growth. Although this does not in itself cast doubt on the validity of the study, the lack of consistency among these findings and those of other studies suggests that a systematic review is warranted. By incorporating information from broadly similar studies, randomerrors can bereduced and ourpractices guided by the best available evidence. ${ }^{1}$ While waiting for the systematic review, this study provides some evidence to support the counselling of women after birth about the value of spacing pregnancies.

\section{Margaret Wallace, RN, MEd Lecturer, Department of Nursing University of Wollongong Wollongong, NSW,Australia}

1 Enkin M, Keirse MJNC, Renfrew M, et al. A guide to effective care in pregnancy and childbirth. Oxford: Oxford University Press, 1995. 